\title{
Taxonomy of Bradysia Winnertz (Diptera, Sciaridae) in the Northern Holarctic, with the description of four new species
}

\author{
Kai HELLER ${ }^{1}$, Heikki HIPPA ${ }^{2}$ \& Pekka VILKAMAA ${ }^{3, *}$ \\ ${ }^{1}$ Erwin-Salomon-Str. 25, D-25451 Quickborn, Germany. E-mail: kaiheller@gmx.de \\ ${ }^{2}$ Gribbylunds allé 2, SE-183 65 Täby, Sweden. E-mail: heikki.hippa@gmail.com \\ ${ }^{3}$ Finnish Museum of Natural History, Zoology Unit, P.O. Box 17, FI-00014 University of Helsinki, \\ Finland. ${ }^{*}$ Corresponding author: pekka.vilkamaa@helsinki.fi \\ ${ }^{1}$ urn:1sid:zoobank.org:author:8F9A2911-A7EC-4CA7-ACAC-E9339D258DE3 \\ ${ }^{2}$ urn:lsid:zoobank.org:author:546524AD-3BD1-4830-842F-EEEE7DF4799B \\ ${ }^{3}$ urn:lsid:zoobank.org:author:A4EAD3B5-DA5E-4C09-8E3A-9289CA7358ED
}

\begin{abstract}
Four species of Bradysia Winnertz (Diptera, Sciaridae) from the Northern Holarctic are described and illustrated for the first time: Bradysia bigeminata sp. nov. (Finland, Canada), B. falciceps sp. nov. (Finland, Canada), B. oelandica sp. nov. (Sweden) and B. plusiospina sp. nov. (Finland). A few Bradysia species, described previously and now found in Northern Europe, are also redefined and illustrated.
\end{abstract}

Key words. Sciaroidea, Holarctic region, biodiversity, systematics, new taxa

Heller K., Hippa H. \& Vilkamaa P. 2015. Taxonomy of Bradysia Winnertz (Diptera, Sciaridae) in the Northern Holarctic, with the description of four new species. European Journal of Taxonomy 122: 1-15. http://dx.doi. org/10.5852/ejt.2015.122

\section{Introduction}

Within the framework of the research project 'Diversity of the Fennoscandian black-winged fungus gnats (Diptera, Sciaridae), financed by the Swedish Taxonomy Initiative, and the research programme 'Deficiently known and threatened forest species' (PUTTE, see Juslén et al. 2008), financed by the Ministry of the Environment, Finland, a number of new species in various genera (Vilkamaa et al. 2013a, b, c), including species of the genus Bradysia Winnertz, 1867, have been found in Northern Europe, while others are new geographical records. Furthermore, conspecific specimens originating from saproxylic studies ongoing in Canada have indicated that some of these species are Holarctic in distribution.

The main aim of this paper is to further expand our knowledge of northern Sciaridae by describing species of Bradysia that are new to science and redescribing others that are new records.

\section{Material and methods}

All specimens of the new species were detected and picked out from unsorted sciarid or general insect material stored in ethanol. Most specimens originated from Malaise trap samples, but some had been 
caught by sweeping or with an aspirator, a photoeclector or pan traps. The specimens were mounted on microscope slides in Euparal, after dehydrating them in absolute ethanol. The terminology and methods of measuring and illustrating morphological structures follow Hippa \& Vilkamaa $(1991,1994)$ and Hippa et al. (2010).

The material is deposited in the following collections:

MZH $=$ Zoological Museum, Finnish Museum of Natural History, Helsinki, Finland

PKHH = Private collection of Kai Heller, Heikendorf, Germany

PRDM = Private collection of Rob Deady, Montréal, Canada

PWMP = Private collection of Werner Mohrig, Poseritz, Germany

SMNH $=$ Swedish Museum of Natural History, Stockholm, Sweden

ZFMK $=$ Zoological Museum Bonn, Germany

\section{Results}

Class Insecta Linnaeus, 1758

Order Diptera Linnaeus, 1804

Superfamily Sciaroidea Billberg, 1820

Family Sciaridae Billberg, 1820

Genus Bradysia Winnertz, 1867

Bradysia Winnertz, 1867: 180.

Type-species: Bradysia angustipennis Winnertz, 1867, by subsequent designation of Enderlein (1911: 127, 183).

Bradysia ascenda Rudzinski, 1994

Fig. 1A-D

\section{Material examined}

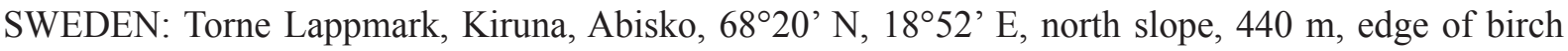
forest, white pan trap, 13-17 Sep. 1991, v. Tschirnhaus, 3 के $\hat{0}$, PWMP.

\section{Redescription (male)}

HEAD. Dark brown, antenna unicolorous pale brown; maxillary palpus very pale brown. Eye bridge 2-3 facets wide. Face with 10-12 scattered longer and shorter setae. Clypeus with 1-4 setae. Maxillary palpus with 3 segments; segment 3 longer than segment 1, segment 2 shortest; segment 1 with 3-4 setae, with dorsal pit of sensilla; antennal flagellomeres with slightly rough surface, body of flagellomere 4 $2.15-2.4 \times$ as long as wide, neck shorter than broad, longest setae longer than width of flagellomere.

Thorax. Dark brown, setae pale. Anterior pronotum with 6-12 setae. Episternum 1 with 13-15 setae. Scutum with long dorsocentrals, with some longer and shorter laterals, scutellum with 2 longer and some short setae.

WING. Fumose. Length $1.8-1.9 \mathrm{~mm}$. Width/length 0.40 . Veins distinct. R1/R 0.65. c/w 0.70-0.75. r-m shorter than bM, r-m with 1 seta, bM non-setose.

Legs. Pale brown. Coxal setae pale. Front tibial organ with pale vestiture forming a row. Front tibial spur longer than tibial width. Claws without teeth. 
ABdomen. Pale brown, setae pale.

Hypopygium (Fig. 1A-D). Brown, concolorous with abdomen.

Gonocoxa. Narrow, longer than gonostylus, mesial margin with normal setosity.

GoNOSTYLUS. Narrow, rather straight, slightly thickened at middle, slightly narrowed towards apex, with mesial side not impressed; with dense apical setosity, without apical tooth, with 8-9 apical-subapical megasetae; megasetae subequal in size, slightly curved and sharp. Tegmen conical, apically truncate, with straight lateral sides, with indistinct basolateral corners, laterally sclerotized, with area of aedeagal teeth. Aedeagal apodeme long.

\section{Remarks}

Bradysia ascenda was described on the basis of three males from the Austrian Alps (Rudzinski 1994). In having its setae pale and in having a distinct sensory pit in the maxillary palpus, it belongs to the Bradysia tilicola group of Menzel \& Mohrig (2000).

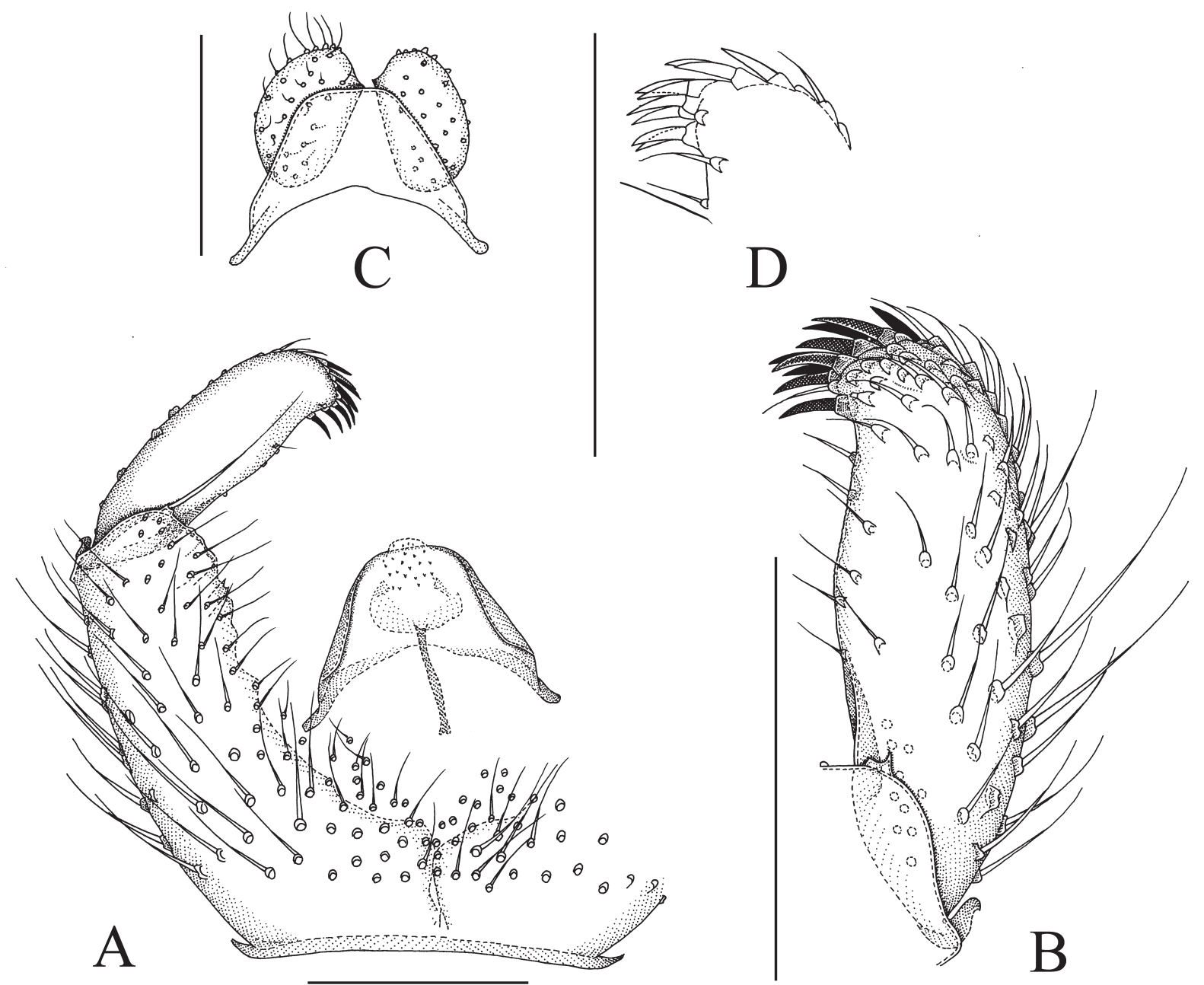

Fig. 1. Bradysia ascenda Rudzinski, 1994 (from Sweden). A. Part of hypopygium, ventral view. B. Gonostylus, ventral view. C. Tegmen and cerci, ventral view. D. Apical part of gonostylus, ventral view. Scales $=0.1 \mathrm{~mm}$. 


\section{Bradysia bigeminata sp. nov. urn:1sid:zoobank.org:act:2B3EB8AC-0D40-48B8-8453-AC9CA78B6316}

Fig. 2A-B

\section{Diagnosis}

Small-sized Bradysia. Dark brown. Maxillary palpus with 2 segments. Wing length $1.5 \mathrm{~mm}$, anal lobe strong. Gonostylus narrow, without apical tooth, with 4 subequal megasetae.

\section{Etymology}

The name is derived from the Latin words bis- (two) and geminus (twin), referring to the two pairs of gonostylar megasetae of the species.

\section{Material examined}

\section{Holotype}

FINLAND: đ̂, Ostrobothnia borealis, Pudasjärvi, Murto-oja (Grid 7267183:3525642), near a brook, Malaise trap, 1 May-3 Jul. 2006, J. Ilmonen \& J. Salmela, MZH.

\section{Paratypes}

FINLAND: Karelia borealis, Kuhmo, Elimyssalo, bred from Fomitopsis rosea collected 23-28 May 1998, A. Komonen, 1 ô, MZH.

CANADA, Ontario, Sudbury Co., Chapleau, Nimitz Forest, from wind thrown Pinus banksiana trees, photoeclector, 10-24 Jul. 2012, R. Deady \& T. Work, 14 ô, 1 [no. 8622] in PKHH, 3 [ZMFKTIS-2527999, ZMFK-TIS-2527999, ZMFK-TIS-2528275] in ZMFK, 1 in MZH, 9 in PRDM; same data

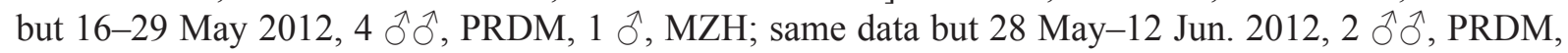
1 ภ, MZH; same data but 25 Apr.-11 Jul. 2012, 2 $\widehat{\partial}$, PRDM; same data but 23 Jul.-8 Aug. 2012, 5 $\widehat{\partial}$, PRDM; same data but 7-20 Aug. 2012, 1 Oे, PRDM; Ontario, Sudbury Co., Chapleau, Superior Forest, mature (99 years old) stand composed of $90 \%$ Pinus banksiana and $10 \%$ P. mariana with an understory shrub layer of Vaccinium, very wet with considerable bryophyte coverage, pine log, photoeclector, 21

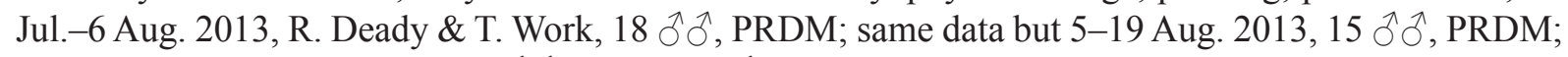
same data but 7-22 Jul. 2013, 2 $\sigma^{\lambda}$, PRDM, 1 ठे, MZH.

\section{Description (male)}

HEAD. Dark brown, antennal flagellomeres unicolorous brown; maxillary palpus very pale brown. Eye bridge 2-3 facets wide. Face with 23 scattered longer and shorter setae. Clypeus with 1 seta. Maxillary palpus with 2 segments; segment 1 longer than segment 2, segment 1 with 1 seta, with dorsal patch of sensilla; surface of antennal flagellomeres smooth, body of flagellomere $42.65 \times$ as long as wide, neck shorter than broad, longest setae longer than width of flagellomere.

Thorax. Dark brown, setae pale. Anterior pronotum with 3 setae. Episternum 1 with 7 setae. Scutum with long dorsocentrals, with some longer and shorter laterals, scutellum with 4 longer and some short setae.

WING. Hyalinous. Length $1.5 \mathrm{~mm}$. Width/length 0.50 . Anal lobe strong. Veins distinct. R1/R 0.55. c/w 0.65. $\mathrm{r}-\mathrm{m}$ and $\mathrm{bM}$ subequal in length, both non-setose.

Legs. Yellow. Coxal setae pale. Front tibial organ with pale vestiture forming a short row. Front tibial spur as long as tibial width. Tibial spurs of middle and hind tibia subequal. Tarsal setosity normal. Claws without teeth. 
AbDomen. Brown, setae pale.

Hypopygium (Fig. 2A-B). Brown, concolorous with abdomen.

Gonocoxa. Basally broad, longer than gonostylus, mesial margin with sparse setosity.

GoNOSTYLUS. Narrow, rather evenly broad and straight, tumid, with mesial side impressed at apical half; with dense apical setosity, without apical tooth, with two pairs of sharp subapical megasetae. Tegmen truncate, with straight lateral sides, laterally and apically sclerotized, with small area of solitary aedeagal teeth. Aedeagal apodeme rather long.

\section{Remarks}

Bradysia bigeminata sp. nov. is here formally assigned to the genus Bradysia because of the presence of a comb-like row of elements in its tibial organ and because of its subequal middle and hind tibial spurs, but it cannot be placed in one of the currently defined species groups. In the structure of its gonostylus it also resembles the species of the Corynoptera vagula group (see Vilkamaa \& Hippa 2006). By its elongated gonostylus with four apical megasetae, and by its short front tibial comb placed in a non-setose area at the apical part of the tibia, Bradysia bigeminata sp. nov. resembles Scatopsciara (Xenopygina) vinea Rudzinski \& Baumann, 2013, but differs in having a simpler tegmen and a different placement of the gonostylar megasetae. In a molecular phylogenetic analysis, the Corynoptera vagula group of species appeared close to species of Scatopsciara Edwards (Shin et al. 2013). In this analysis, no species of Scatopsciara (Xenopygina) Frey, 1942 was included. It is obvious that a more inclusive analysis is needed to clarify the relationships of B. bigeminata sp. nov., the Corynoptera vagula group and the species currently placed in Scatopsciara (Xenopygina).
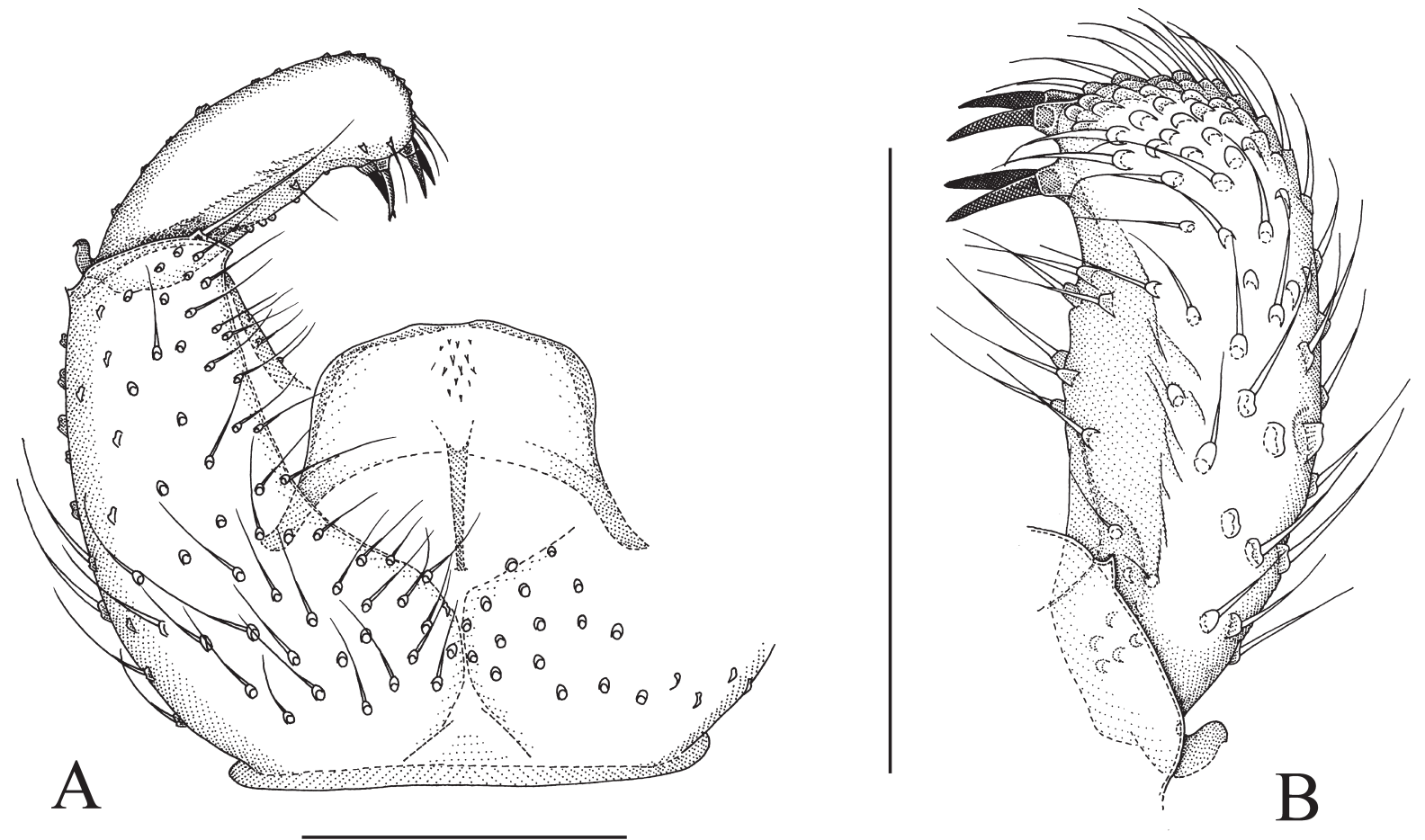

Fig. 2. Bradysia bigeminata sp. nov. (holotype). A. Part of hypopygium, ventral view. B. Gonostylus, ventral view. Scales $=0.1 \mathrm{~mm}$. 


\section{Ecology and distribution}

Bradysia bigeminata sp. nov. was found to be very numerous in deadwood sampled in Canada. This may suggest deadwood to be the natural habitat of the species. The COI sequence of the collected specimens was allocated to the BIN ACA4746 on BOLD (www.boldsystems.org), and, interestingly, the results showed that the species is widely distributed in Eastern Canada.

Bradysia chlorocornea Mohrig \& Menzel, 1992

Fig. 3A-B

\section{Material examined}

FINLAND: Regio kuusamoensis, Kuusamo, Kuohusuo-Kalliovaara $30 \mathrm{~km} \mathrm{~S}$ of Kuusamo, $65.43^{\circ} \mathrm{N}$, $29.05^{\circ}$ E, 270 m, spruce/birch swamp forest, Malaise trap, 2-15 Aug. 2004, M. \& C. Jaschhof, 4 §ठ, $\mathrm{MZH}$.

\section{Redescription (male)}

HEAD. Brown, antennal flagellomeres 1-2 yellow, scapus, pedicellus and flagellomere 3-14 pale brown; maxillary palpus very pale brown. Eye bridge 3 facets wide. Face with 10-15 scattered longer and shorter setae. Clypeus with 1-3 setae. Maxillary palpus with 3 segments; segment 1 longer than segment 3 , segment 2 shortest; segment 1 with 3-4 setae, with dorsal patch of sensilla; surface of antennal flagellomeres smooth, body of flagellomere $42.3-2.7 \times$ as long as wide, neck shorter than broad, longest setae as long as width of flagellomere.

Thorax. Brown, setae pale. Anterior pronotum with 3-8 setae. Episternum 1 with 7-15 setae. Scutum with long dorsocentrals, with some longer and shorter laterals, scutellum with 2 longer and some short setae.
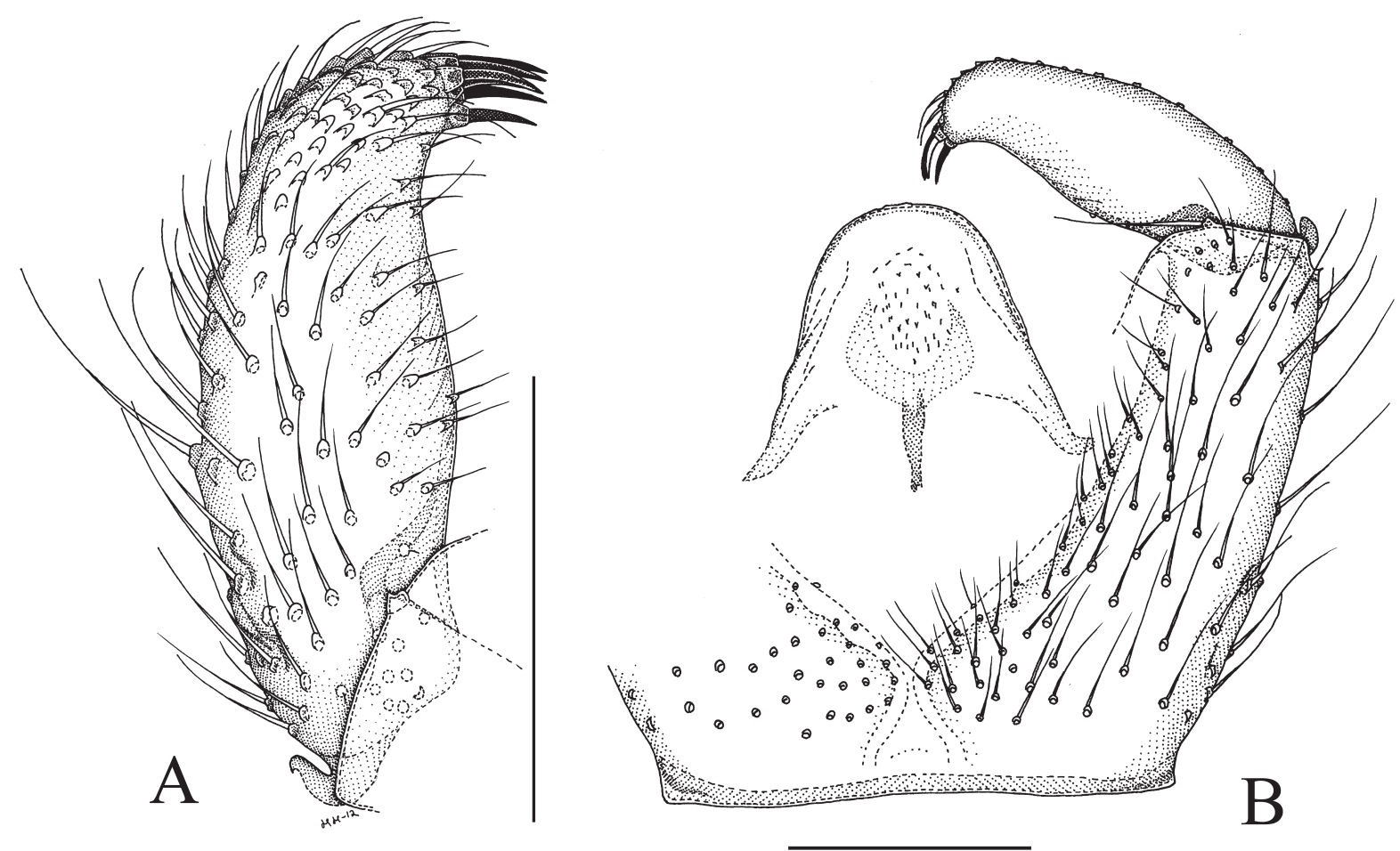

Fig. 3. Bradysia chlorocornea Mohrig \& Menzel, 1992 (from Finland). A. Gonostylus, ventral view. B. Part of hypopygium, ventral view. Scales $=0.1 \mathrm{~mm}$. 
Wing. Hyalinous. Length $1.7-1.9 \mathrm{~mm}$. Width/length 0.40 . Veins distinct. R1/R 0.70-0.85. c/w $0.70-$ 0.80. $\mathrm{r}-\mathrm{m}$ and $\mathrm{bM}$ subequal in length. $\mathrm{bM}$ non-setose, $\mathrm{r}-\mathrm{m}$ non-setose or with 1 seta.

Legs. Yellow. Coxal setae pale. Front tibial organ with pale vestiture forming a short row. Front tibial spur slightly longer than tibial width. Claws with teeth.

Abdomen. Pale brown, setae pale.

Hypopygium (Fig. 3A-B). Brown, concolorous with abdomen.

GonocoXa. Narrow, longer than gonostylus, mesial margin with rather dense setosity.

GoNOSTYLus. Narrow, broadest at middle, narrowed towards apex, with mesial side weakly impressed at apical half; with dense apical setosity, without apical tooth, with 5-6 apical megasetae whip-lash in form. Tegmen conical, apically roundish, with straight lateral sides, weakly sclerotized, with large area of aedeagal teeth, laterally straight. Aedeagal apodeme short.

\section{Remarks}

Bradysia chlorocornea was described from three males from Japan (Mohrig et al. 1992). By having bi-coloured antennal flagellomeres and the tarsal claws with teeth, it belongs to the Bradysia fungicola group of Menzel \& Mohrig (2000). By its slender gonostylus with an apical group of slender, subequal megasetae it resembles B. affinis (Zetterstedt, 1838), but it can be distinguished by having the megasetae more slender and longer.

\section{Bradysia falciceps sp. nov. \\ urn:1sid:zoobank.org:act:60FA7B62-2FFA-43FE-A5A2-5AC02CF29B13}

Fig. 4A-B

\section{Diagnosis}

Small-sized Bradysia. Brown. Maxillary palpus with 3 segments, segment 1 with shallow sensory area. Wing length $1.5-1.7 \mathrm{~mm}$, veins indistinct. Gonostylus narrow, mesially impressed, with apical tooth and 5-6 megasetae in one group.

\section{Etymology}

The name is derived from the Latin words falx (scythe) and -ceps (of the head), referring to the curved apical tooth of the gonostylus of the species.

\section{Material examined}

\section{Holotype}

FINLAND: ${ }^{\Uparrow}$, Lapponia inariensis, Utsjoki, tundra, Malaise trap, 14 Aug. 2000, Fatouros, MZH.

\section{Paratypes}

FINLAND: Same data as holotype, 1 ๙ , PKHH 3368; Regio aboensis, Turku, Pomponrahka (Grid 6719377:3240217), open bog, Malaise trap, 1 Aug.-28 Sep. 2011, J. Salmela, 1 đૈ, MZH.

CANADA: Ontario, Sudbury Co., Chapleau, Superior Forest, mature (99 years old) stand composed of 90\% Pinus banksiana and 10\% P. mariana with an understory shrub layer of Vaccinium, very wet, with considerable bryophyte coverage, photoeclector on pine log, 23 Jun.-8 Jul. 2013, R. Deady \& T. Work,

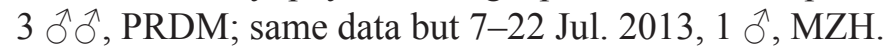




\section{Description (male)}

HEAD. Brown, antennal flagellomeres 1-2 yellow, scapus, pedicellus and flagellomeres 3-14 unicolorous pale brown; maxillary palpus very pale brown. Eye bridge 3 facets wide. Face with 15-21 scattered longer and shorter setae. Clypeus with 1-2 setae. Maxillary palpus with 3 segments; segment 3 longer than segment 1, segment 2 shortest; segment 1 with 1-2 setae, with small shallow dorsal sensory area; surface of antennal flagellomeres smooth, body of flagellomere $41.85-2.3 \times$ as long as wide, neck shorter than broad, longest setae as long as width of flagellomere.

Thorax. Brown, setae pale. Anterior pronotum with 4-7 setae. Episternum 1 with $8-9$ setae. Scutum with long dorsocentrals, with some longer and shorter laterals, scutellum with 4 longer and some short setae.

WING. Hyalinous. Length $1.5-1.7 \mathrm{~mm}$. Width/length $0.45-0.50$. Veins indistinct. R1/R $0.60-0.65$. c/w 0.75-0.85. r-m and bM subequal in length. r-m with 1-2 setae, bM non-setose.

Legs. Yellow. Coxal setae pale. Front tibial organ with pale vestiture forming short row. Front tibial spur longer than tibial width. Claws without teeth.

Abdomen. Pale brown, setae pale and fine.

Hypopygium (Fig. 4A-B). Brown, concolorous with abdomen.

GonocoXa. Narrow, longer than gonostylus, mesial margin with normal setosity.

GonOsTYLus. Narrow, evenly straight, with shallow lateral notch at apical fourth, with mesial side impressed at all its length; with dense apical setosity, with strong curved apical tooth-like megaseta,
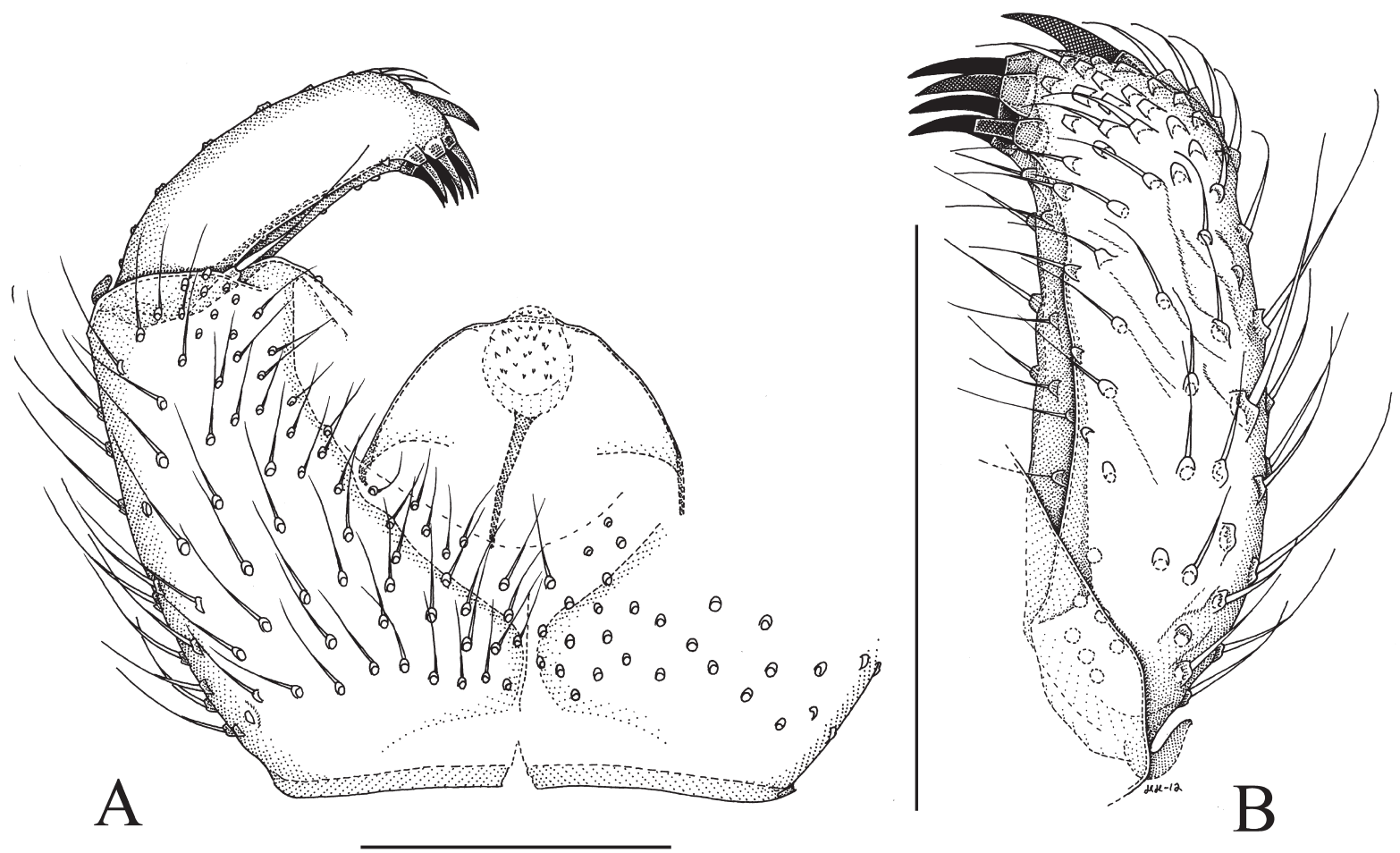

Fig. 4. Bradysia falciceps sp. nov. (holotype). A. Part of hypopygium, ventral view. B. Gonostylus, ventral view. Scales $=0.1 \mathrm{~mm}$. 
with 5-6 subapical megasetae, megasetae sharp, in single group. Tegmen conical, weakly sclerotized, with area of aedeagal teeth. Aedeagal apodeme long.

\section{Remarks}

Bradysia falciceps sp. nov. belongs to the Bradysia praecox group and is most similar to B. nitidicollis (Meigen, 1818), B. iridipennis (Zetterstedt, 1938) and B. quercina Menzel \& Köhler, 2014 by sharing a strong apical tooth at the dorsoapical part of the gonostylus (see Köhler et al. 2014). Bradysia falciceps sp. nov. can be distinguished from all other species of the B. praecox group in having pale basal antennal flagellomeres with dark necks.

\section{Bradysia oelandica sp. nov. urn:1sid:zoobank.org:act:D1390D14-F74E-4595-A927-A287B8A331DF}

Fig. $5 \mathrm{~A}-\mathrm{C}$

\section{Diagnosis}

Large-sized Bradysia. Brown. Maxillary palpus with 3 segments, segment 1 with a small shallow sensory patch. Wing length $2.3 \mathrm{~mm}$, anal lobe small. Setose intercoxal lobe of hypopopygium present. Gonocoxa and gonostylus broad; gonocoxa with elongated ventromesial setae; gonostylus bulged mesiad, with a short apical tooth.

\section{Etymology}

The name is derived from the Latinized name of the type locality (the island of Öland, Sweden) of the species.

\section{Material examined}

\section{Holotype}

SWEDEN: ${ }^{\top}$, Öland, Mörbylonga, Gamla Skogsby (Kalkstad), 56³7.002' N, 16³0.457’ E, meadow with bushes, Malaise trap (Trap ID 22), 20 May-28 Jun. 2006, Swedish Malaise Trap Project, SMNH 2652.

\section{Description (male)}

HEAD. Dark brown, antennal flagellomeres unicolorous, paler brown; maxillary palpus very pale brown. Eye bridge 3 facets wide. Face with 15 scattered longer and shorter setae. Clypeus with 3 setae. Maxillary palpus with 3 segments; segment 1 longer than segment 3 , segment 2 shortest; segment 1 with 3 setae, with small dorsal patch of sensilla in shallow depression; surface of antennal flagellomeres rough, body of flagellomere $42.9 \times$ as long as wide, neck shorter than broad, longest setae as long as width of flagellomere.

Thorax. Brown, setae dark. Anterior pronotum with 7 setae. Episternum 1 with 6 setae. Scutum with long dorsocentrals, with some longer and shorter laterals, scutellum with short setae.

Wing. Fumose. Length $2.3 \mathrm{~mm}$. Width/length 0.45 . Anal lobe small. Veins distinct. R1/R 0.75. c/w 0.70 . r-m shorter than bM, both non-setose.

Legs. Yellowish brown. Coxal setae pale. Front tibial organ with pale vestiture forming a row. Front tibial spur longer than tibial width. Claws without teeth.

Abdomen. Setae dark and long. 
Hypopygium (Fig. 5A-C). Brown, concolorous with abdomen. Intercoxal area with lobe and possessing ca. 10 long setae.

Gonocoxa. Broad, longer than gonostylus, ventromesial margin with elongated setae, dorsomesial margin with distinct lobes.

GonostyLus. Globular, medially bulged mesiad, with dense apical setosity, with short narrow apical tooth, with apical (lateral) megaseta, with specialized subapical seta. Tegmen conical, weakly sclerotized, with area of small aedeagal teeth. Aedeagal apodeme short but strong.

\section{Remarks}

Bradysia oelandica sp. nov. belongs to the Bradysia polonica group of Menzel \& Mohrig (2000) in having a broad intercoxal lobe of the hypopygium and an indistinct apical tooth at the end of the gonostylus. The general structure of the gonostylus is fairly similar to the other species of that group, but $B$. oelandica sp. nov. is easy to distinguish by the elongated setae at the apical part of the gonocoxa.

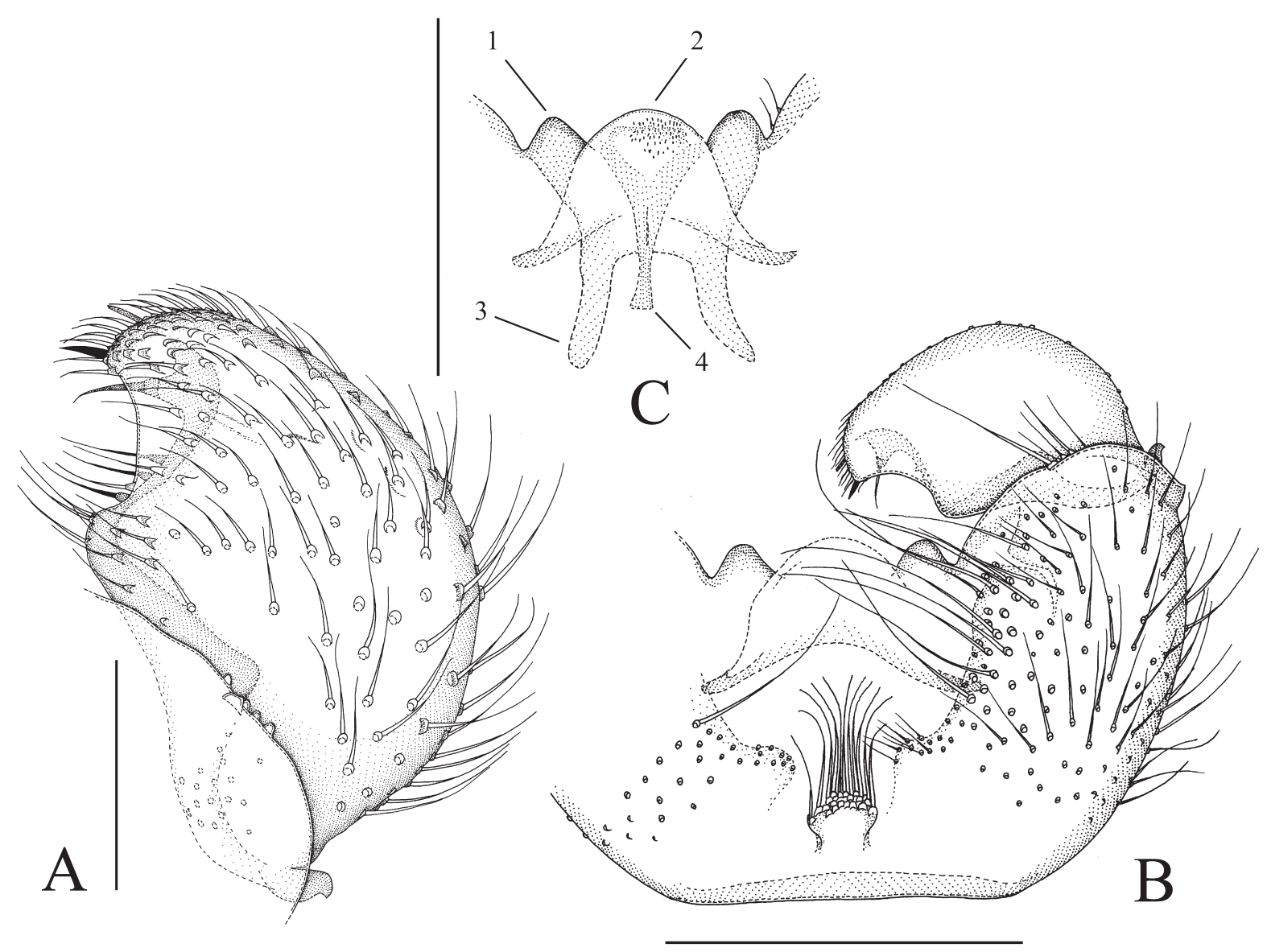

Fig. 5. Bradysia oelandica sp. nov. (holotype). A. Gonostylus, ventral view. B. Part of hypopygium, ventral view. C. Medial parts of hypopygium, ventral view. Scale bars: $A=0.1 \mathrm{~mm}, \mathrm{~B}-\mathrm{C}=0.3 \mathrm{~mm}$. $1=$ lobe at dorsal mesial margin of gonocoxa, $2=$ tegmen, $3=$ gonocoxal apodeme, $4=$ aedeagal apodeme. 


\section{Bradysia plusiospina sp. nov. urn:1sid:zoobank.org:act:9EFEEAC1-6A5A-49FA-881B-1AA96CA76C28}

Fig. 6A-B

\section{Diagnosis}

Medium-sized Bradysia. Brown. Maxillary palpus with 3 segments, segment 1 with a dorsal patch of sensilla. Wing length $1.8-1.9 \mathrm{~mm}$, anal lobe small. Gonocoxa and gonostylus narrow, gonostylus straight, mesially weakly impressed, without apical tooth, with 7 sharp megasetae in two groups.

\section{Etymology}

The name is derived from the Latinized Greek word plousious (wealthy), and the Latin word spina (spine), referring to the many gonostylar megasetae of the species.

\section{Material examined}

\section{Holotype}

FINLAND: $\widehat{\jmath}$, Ostrobothnia borealis, Tervola, Yrttijänkä (Grid 7346827:340814), near a spring, Malaise trap, 1-28 Jun. 2004, J. Salmela, MZH.

\section{Paratype}

FINLAND: same data as holotype, $\hat{\jmath}, \mathrm{MZH}$.
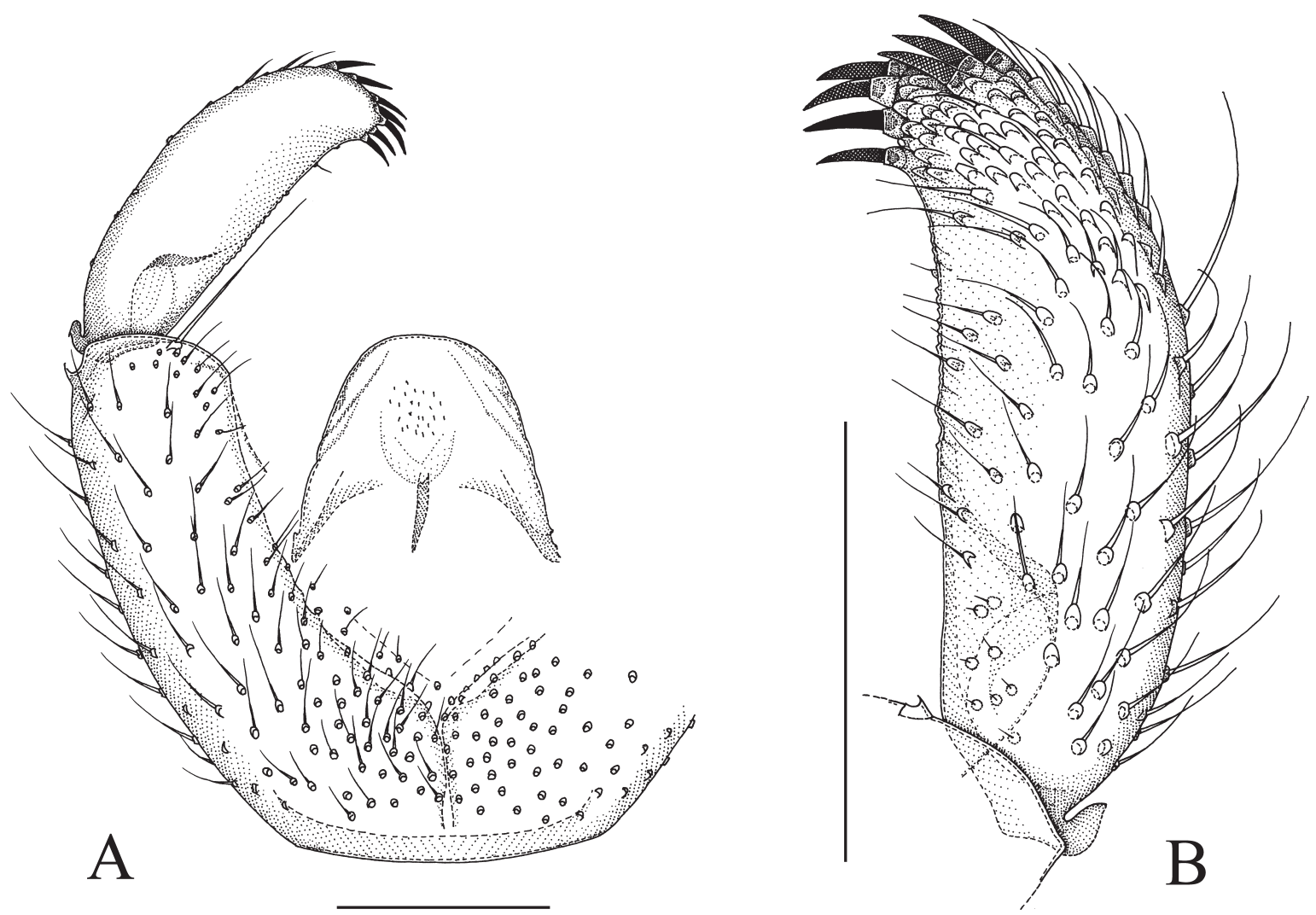

Fig. 6. Bradysia plusiospina sp. nov. (holotype). A. Part of hypopygium, ventral view. B. Gonostylus, ventral view. Scales $=0.1 \mathrm{~mm}$. 


\section{Description (male)}

HEAD. Brown, antennal flagellomeres unicolorous, paler brown, maxillary palpus very pale brown. Eye bridge 3 facets wide. Face with 31-40 scattered longer and shorter setae. Clypeus with 1 seta. Maxillary palpus with 3 segments; segment 1 longer than segment 3, segment 2 shortest; segment 1 with 4-6 setae, with dorsal patch of sensilla; surface of antennal flagellomeres smooth, body of flagellomere $43.1 \times$ as long as wide, neck shorter than broad, longest setae slightly longer than the width of flagellomere.

Thorax. Brown, setae pale. Anterior pronotum with 6-7 setae. Episternum 1 with 8-9 setae. Scutum with long dorsocentrals, with some longer and shorter laterals, scutellum with 2 longer and some short setae.

WING. Fumose. Length 1.8-1.9 mm. Width/length 0.40. Anal lobe small. Veins distinct. R1/R 0.80. c/w $0.60-0.70$. r-m and bM subequal in length. r-m with 1 seta, bM non-setose.

Legs. Yellow. Coxal setae pale. Front tibial organ with pale vestiture forming short row. Front tibial spur longer than tibial width. Claws without teeth.

Abdomen. Pale brown, setae pale and short.

Hypopygium (Fig. 6 A-B). Brown, concolorous with abdomen.

Gonocoxa. Narrow, longer than gonostylus, mesial margin with short setosity.

GoNOSTYLus. Narrow, rather straight, slightly narrowed and curved towards apex, with mesial side weakly impressed; with dense apical setosity, without apical tooth, with 7 megasetae, megasetae in apical and subapical groups, subequal in size, sharp. Tegmen truncate, with straight lateral sides, weakly sclerotized, with area of aedeagal teeth. Aedeagal apodeme short.

\section{Remarks}

Bradysia plusiospina sp. nov. resembles B. pseudocampestris Mohrig, 1978 and B. angustata Tuomikoski, 1960 in the general form of the hypopygium and gonostylus, as well as in having the anal lobe of the wing poorly developed. Bradysia angustata differs from the others in having an apical tooth and slightly stronger megasetae in its gonostylus, and in having its wing even narrower than the others. Bradysia plusiospina sp. nov. can be distinguished from B. pseudocampestris in having stronger megasetae, some megasetae in a more lateral position than in the latter species and in having a more setose basal part of its hypopygium (see Mohrig 1978: figs 4, 7). Bradysia plusiospina sp. nov. is placed in the Bradysia fungicola group of Menzel \& Mohrig (2000).

Bradysia quercina Menzel \& Köhler, 2014

Fig. 7A-C

\section{Material examined}

Paratypes

SWEDEN: Småland, Gränna, Lönnemålen, $58^{\circ} 02.935^{\prime}$ N, $14^{\circ} 34.382^{\prime}$ E, next to old cellar in Norway Spruce forest, Malaise trap (Trap ID 17), 10-24 Sep. 2003, Swedish Malaise Trap Project, $3 \hat{\jmath} \widehat{\partial}$, no. 3184, 3185, SMNH, 4103, MZH; Småland, Kalmar län, Bäckebo, Grytsjön Nature Reserve, old aspen forest in boulder terrain, Malaise trap, 15 Jun. 2006, Swedish Malaise Trap Project, 1 đ̊, SMNH 6781.

SWITZERLAND: Sihlwald near Zürich, window trap, 5 Jun. 1996, Schiegg, 1 ô, PKHH 1805. 


\section{Remarks}

Bradysia quercina Menzel \& Köhler, 2014 was described as belonging to the Bradysia praecox group on the basis of a number of specimens from Norway, Italy, Sweden and Switzerland (Köhler et al. 2014), and its affinities were thoroughly discussed. To compare to the figures of the holotype provided in the original description, we present drawings of the hypopygium and gonostylus of a paratype from Sweden (Fig. 7).

\section{Discussion}

Bradysia is by far the most species-rich genus of Sciaridae, including about 400 species worldwide, most in the Palaearctic region. With the present new species included, about 70 species are known from both Finland and Sweden. In the Nearctic region, only 20 species are known (Mohrig et al. 2013). This is a strongly biased figure and our current knowledge of the Nearctic fauna is still very incomplete. Even less is known of Bradysia from other biogeographical regions (see Vilkamaa et al. 2012). The newly described species show that even in the areas for which the sciarid fauna is best known, new species can be discovered. With many of the species morphologically very similar to each other, the genus is probably the most challenging of all Sciaridae regarding its taxonomy. The Holarctic fauna has been divided into sixteen species groups (Menzel \& Mohrig 2000), but these have been formed mainly based on general similarity. A recent phylogeny based on molecular characters challenges even the monophyly of the genus (Shin et al. 2013).
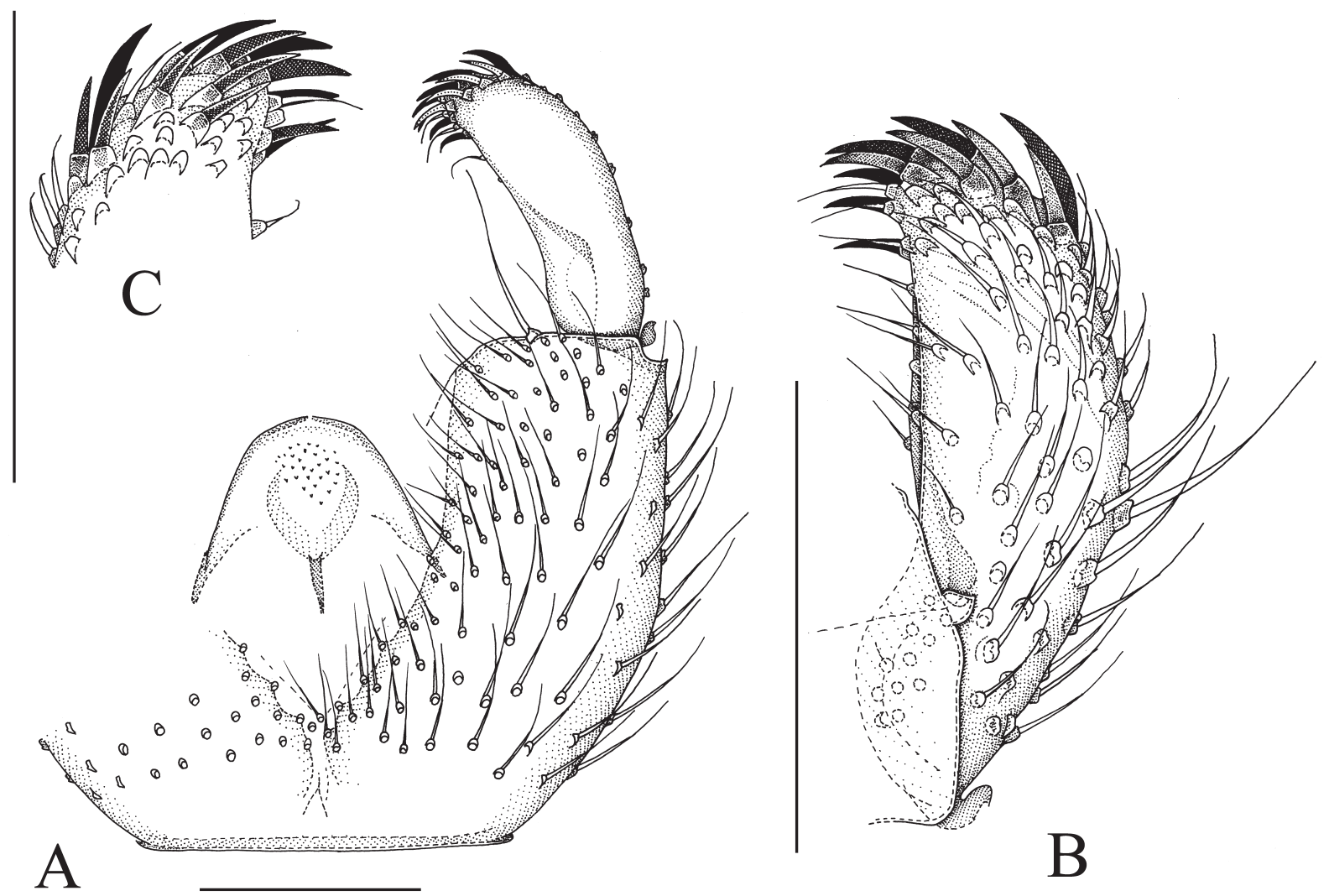

Fig. 7. Bradysia quercina Menzel \& Köhler, 2014 (from Sweden). A. Part of hypopygium, ventral view. B. Gonostylus, ventral view. C. Apical part of gonostylus, ventral view. Scales $=0.1 \mathrm{~mm}$. 


\section{Acknowledgements}

We thank Rob Deady (Montréal, Canada), Werner Mohrig (Poseritz, Germany) and Jukka Salmela (Rovaniemi, Finland) for materials and Björn Rulik (Bonn, Germany) for doing the DNA analyses. This work was supported by the Swedish Taxonomy Initiative. Rob Deady kindly checked the English.

\section{References}

Enderlein G. 1911. Die phyletischen Beziehungen der Lycoriiden (Sciariden) zu den Fungivoriden (Mycetophiliden) und Itonididen (Cecidomyiiden) und ihre systematische Gliederung. Archiv für Naturgeschichte 77, Suppl. 3: 116-201. http://www.biodiversitylibrary.org/item/52219\#page/908/ mode/1up [accessed 21 April 2015]

Hippa H. \& Vilkamaa P. 1991. The genus Prosciara Frey (Diptera, Sciaridae). Entomologica Fennica 2: $113-155$.

Hippa H. \& Vilkamaa P. 1994. The genus Camptochaeta gen. n. (Diptera, Sciaridae). Acta Zoologica Fennica 194: 1-85.

Hippa H., Vilkamaa P. \& Heller K. 2010. Review of the Holarctic Corynoptera Winnertz, 1867, s. str. (Diptera, Sciaridae). Zootaxa 2695: 1-197.

Juslén A., Kuusinen M, Muona J., Siitonen J. \& Toivonen H. 2008. Puutteellisesti tunnettujen ja uhanalaisten metsälajien tutkimusohjelma [Research Programme of Deficiently Known and Threatened Forest Species] (PUTTE). Suomen Ympäristö 1: 1-146.

Köhler A., Menzel F., Thunes K.H. \& Søli G.E.E. 2014. Black fungus gnats (Diptera: Sciaridae) in oak canopies: description of Bradysia quercina Menzel \& Köhler spec. nov. and new records for Norway. Studia Dipterologica 20: 325-331.

Menzel F. \& Mohrig W. 2000. Revision der paläarktischen Trauermücken (Diptera: Sciaridae). Studia Dipterologica, Suppl. 6 (for 1999): 1-761.

Mohrig W. 1978. Zur Kenntnis flügelreduzierter Dipteren der Bodenstreu. IX. Beitrag: Gattungen Corynoptera, Bradysia und Plastosciara (Sciaridae). Zoologischer Anzeiger 201: 424-432.

Mohrig W., Menzel F. \& Kozánek M. 1992. Neue Trauermücken (Diptera, Sciaridae) aus Nord-Korea und Japan. Dipterological Research 3: 17-32.

Mohrig W., Heller K., Hippa H., Vilkamaa P. \& Menzel F. 2013. Revision of the black fungus gnats (Diptera: Sciaridae) of North America. Studia Dipterologica 19: 141-286.

Rudzinski H.-G. 1994. Neue Mitteilungen zur Trauermückenfauna Österreichs (Diptera Nematocera: Sciaridae). Entomofauna, Zeitschrift für Entomologie 15: 281-292.

Shin S., Jung S., Menzel F., Heller K., Lee H. \& Lee S. 2013. Molecular phylogeny of black fungus gnats (Diptera: Sciaroidea: Sciaridae) and the evolution of larval habitats. Molecular Phylogenetics and Evolution 66: 833-846. http://dx.doi.org/10.1016/j.ympev.2012.11.008

Tuomikoski R. 1960. Zur Kenntnis der Sciariden Finnlands. Annales Zoologici Societatis Zoologiae Botanicae Fennicae ,Vanamo' 21 (4): 1-164.

Vilkamaa P. \& Hippa H. 1996. Review of the genus Prosciara Frey (Diptera, Sciaridae) in the Indomalayan region. Acta Zoologica Fennica 203: 1-57.

Vilkamaa P. \& Hippa H. 2006. Corynoptera vagula Tuomikoski and allied species (Diptera: Sciaridae). Zootaxa 1150: 31-42. 
Vilkamaa P., Hippa H. \& Mohrig W. 2012. The genus Bradysia Winnertz (Diptera, Sciaridae) in New Caledonia, with the description of thirteen new species. Zootaxa 3489: 25-44.

Vilkamaa P., Hippa H. \& Heller K. 2013a. Review of the genus Camptochaeta Hippa \& Vilkamaa (Diptera, Sciaridae), with the description of nine new species. Zootaxa 3636: 476-488. http://dx.doi. org/10.11646/zootaxa.3636.3.6

Vilkamaa P., Hippa H. \& Heller K. 2013b. Notes on the taxonomy of the Holarctic Corynoptera Winnertz sensu lato (Diptera, Sciaridae), with description of six new species. Zootaxa 3710: 322-332. http:// dx.doi.org/10.11646/zootaxa.3710.4.2

Vilkamaa P., Hippa H. \& Heller K. 2013c. Taxonomy of the Sciaridae (Diptera) of Northern Europe: description of eight new species. Studia Dipterologica 20: 47-58.

Winnertz J. 1867. Beitrag zu einer Monographie der Sciarinen. Zoologisch-Botanischen Gesellschaft in Wien, Vienna.

Manuscript received: 6 February 2015

Manuscript accepted: 25 March 2015

Published on: 8 May 2015

Topic editor: Koen Martens

Desk editor: Danny Eibye-Jacobsen

Printed versions of all papers are also deposited in the libraries of the institutes that are members of the EJT consortium: Muséum National d'Histoire Naturelle, Paris, France; Botanic Garden Meise, Belgium; Royal Museum for Central Africa, Tervuren, Belgium; Natural History Museum, London, United Kingdom; Royal Belgian Institute of Natural Sciences, Brussels, Belgium; Natural History Museum of Denmark, Copenhagen, Denmark. 